\title{
Pelatihan Pengolahan Nugget Sayuran Untuk Meningkatkan Produktivitas Anggota Pendamping Keluarga Harapan Di Desa Jatinom-Blitar
}

\author{
Rosidi Azis $^{(1)}$, Lestariningsih ${ }^{(2)}$ \\ ${ }^{1,2}$ Universitas Nahdlatul Ulama Blitar \\ Email: ${ }^{1}$ rosialfatih@ymail.com, ${ }^{2}$ tariunu@gmail.com
}

$\overline{\text { Tersedia Online di }}$
http://www.jurnal.unublitar.ac.id/
index.php/briliant

Sejarah Artikel

Diterima pada 10 April 2018

Disetuji pada 8 Mei 2018

Dipublikasikan pada 13 Mei

2018 Hal. 230-236

\begin{tabular}{l}
\hline Kata Kunci: \\
\hline pendamping PKH, produktivitas, \\
nugget sayuran,
\end{tabular}

\section{DOI:}

http://dx.doi.org/10.28926/briliant .$v 3 \mathrm{i} 2.176$

\begin{abstract}
Abstrak: Program Keluarga Harapan (PKH) adalah cara pemerintah untuk mengentaskan kemiskinan. Perjalanan PKH dirasa kurang optimal oleh karena kurangnya pengetahuan pendamping. Berdasarkan hasil observasi dan wawancara anggota $\mathrm{PKH}$ Jatinom, Kabupaten Blitar yaitu dibutuhkan peningkatan pengetahuan (SDM), keterampilan dan jiwa usaha. Nugget sebagai makanan yang cepat saji (fast-food) yang cukup disukai oleh semua kalangan masyarakat. Tujuan dari pengabdian masyarakat ini adalah memberikan pengetahuan, keterampilan dan menumbuhkan jiwa usaha anggota pendamping PKH Jatinom Kabupaten Blitar dengan pelatiahan pembuatan nugget sayuran yang aman dan sehat. Metode palaksanaan yaitu mulai tahapan persiapan, pelaksanaan dan evaluasi. Hasil dari pengabdian ini yaitu 1) anggota $\mathrm{PKH}$ mendapatkan pengetahuan tentang pembuatan nugget sayuran, 2) anggota PKH mampu mengemas (packaging) dengan baik dan strategi pemasaran produk nugget sayuran.
\end{abstract}

Program keluarga harapan $(\mathrm{PKH})$ merupakan salah satu cara pemerintah untuk mengentaskan masalah kemiskinan. Program PKH merupakan program kementrian sosial RI yang dilaksanakan sejak tahun 2007. Tujuan dari adanya PKH ini yaitu untuk meningkatkan kualitas sumber daya manusia dengan memberikan dana tunai kepada keluarga yang telah memenuhi syarat. Fokus dari pemberian dana $\mathrm{PKH}$ ini adalah rumah tangga atau keluarga yang sangat miskin yang ditetapkan selama 6 tahun. Apabila keluarga penerima dana PKH tersebut masih dalam kondisi miskin, maka diberi tambahan waktu selam 3 tahun lagi untuk menerima dana PKH. Selanjutnya baru dilakukan pemutusan sebagai penerima dana PKH.

Salah satu yang menjadi sasaran program PKH yaitu Desa Jatinom. Desa Jatinom merupakan salah satu desa yang terletak di Kecamatan Kanigoro Kabupaten Blitar. Perjalanan PKH di Jatinom bisa dikatakan belum sepenuhnya berhasil. Ada beberapa faktor yang menjadi indikasi yaitu pengetahuan pendamping yang terbatas terhadap persoalan yang dihadapi oleh penerima dana dan lemahnya koordinasi antar ke dua belah pihak. Oleh sebab itu, salah satu cara untuk meningkatkan produktivitas pendamping yaitu diadakan pelatihan kewirausahaan. Pelatihan kewirausahaan ini bertujuan untuk menumbuhkan jiwa usaha, keterampilan serta kreativitas anggota PKH pada hal-hal yang sederhana yaitu pelatihan pembuatan nugget. 
Nugget merupakan makanan siap saji (fast food) yang sudah sangat terkenal dan sangat di gemari oleh semua kalangan baik anak-anak hingga orang dewasa (Abustam \& Ali, 2005; Buckle, Edwards, Fleet, \& Wootton, 1987). Akhirakhir ini timbulnya kesadaran masyarakat akan dampak rofessi yang ditimbulkan dari makanan yang tergolong "fast food" (Ratnani, 2009; Saparinto \& Hidayati, 2006). Menyikapi kekhawatiran masyarakat terhadap makanan siap saji tersebut, maka di rasa perlu untu membuat produk yang ASUH (aman, sehat, utuh dan higienis). Salah satu caranya yaitu mengganti komposisi bahan dasar nugget dengan bahan sehat, kaya serat dan berasal dari alam yaitu sayur-sayuran. Selain tinjauan dari aspek kesehatan, sayuran sangat mudah untuk di dapat dengan harga yang sangat terjangkau (Yuyun, 2007). Atas dasar tersebut nugget sayuran dapat dijadikan sebagai terobosan usaha bagi anggota pendamping $\mathrm{PKH}$ untuk memproduksi nugget sayuran. Dengan demikian tujuan dari ada pelatihan ini yaitu anggota pendamping PKH dapat mengolah nugget sayuran untuk memberikan produk fast food yang aman terhadap kesehatan.

\section{METODE}

Peningkatan kualitas sumber daya manusia, penerapan teknologi tepat guna dalam usaha produksi nugget sayuran dan pendampingan kelembagaan merupakan kebutuhan masyarakat sasaran program PKM ini. Metode pelaksanaan dari kegiatan ini adalah pelatihan pembuatan nugget sayuran sebagai upaya peningkatan kualitas SDM pendamping PKH. Kegiatan ini dilaksanakan di Desa Jatinom Kecamatan Kanigoro Kabupaten Blitar pada bulan Januari 2018. Adapun bahan-bahan yang digunakan dalam pelatihan pengolahan nugget sayuran terdiri dari wortel, brokoli, telur, tepung tapioca, margarin, garam, gula, lada, tepung roti. Peralatan yang digunakan yaitu penggorengan, oven, blender, pisau, baskom, sendok dan kompor.

\section{Tahapan Pelaksanaan Program}

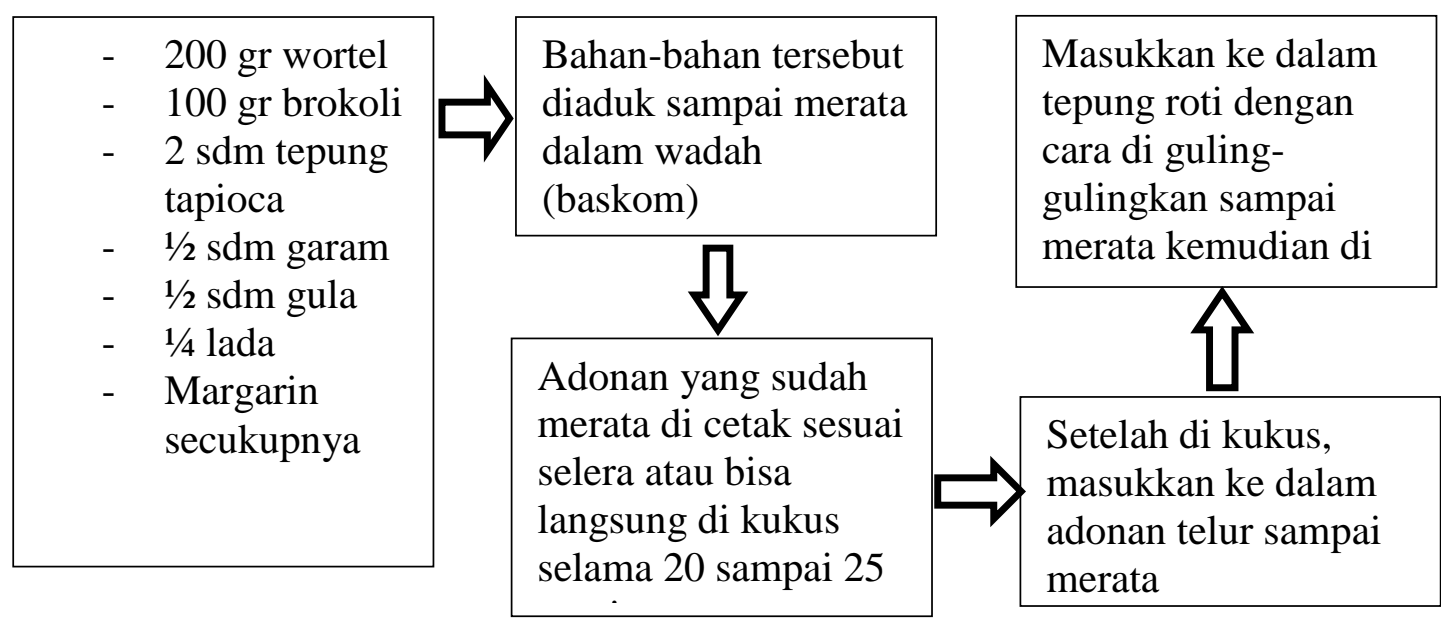

\section{Monitoring dan Evaluasi}

Kegitan monitoring dan Evaluasi program PKH akan dilaksanakan setiap satu bulan sekali pada akhir rofe minggu ke-4. Kegiatan monitoring dan evaluasi merupakan suatu wadah diskusi antara tim pelaksana pelatih program dengan 
anggota pendamping PKH sasaran tentang sejauh mana penerimaan materi pelatihan yang telah dilaksanakan. Hasil monitoring dan evaluasi digunakan acuhan dalam menentukan pelaksanaan program di bulan berikutnya.

\section{HASIL}

Pengolahan nugget seyuran meliputi beberapa tahapan yaitu tahapan persiapan, pelaksanaan program, monitoring dan evaluasi.

\section{Tahapan Persiapan}

Pelaksanaan program pengabdian ini, sebelumnya kami melaksanakan survey terlebih dahulu kepada kelompok keluarga harapan di Desa Jatinom, Blitar pada taggal 24 Desember 2017. Observasi dan wawancara dilakukan pada tanggal 7 Januari 2018. Analisis kebutuhan, diharapkan sesuai dengan kebutuhan kelompok keluarga harapan.

Hasil observasi dan wawancara terhadap anggota pendamping PKH yaitu a) dibutuhkan peningkatan mutu kualitas SDM untuk mencapai kemandirian dan kesejahteraan. b) dibutuhkan adanya pelatihan dan pendampingan kemandirian masyarakat dalam melola usaha secara mandiri dan professional. c) kurangnya pengetahuan anggota PKH dalam keterampilan pembuatan produk inovatif yang aman dan sehat.

\section{Tahap Pelaksanaan}

Kegiatan pengabdian kepada masyarakat ini dilaksanakan dengan metode sosialisasi, pelatihan dan pendampingan pembuatan nugget sayuran. Pada hatapan ini adalah sebagai berikut:

Tabel 1 Tahapan Pelaksanaan

\begin{tabular}{|c|c|c|c|c|}
\hline No & Kegiatan & Metode & Target & Anggota PKH \\
\hline 1 & $\begin{array}{l}\text { Memberikan } \\
\text { pengetahuan tentang } \\
\text { tahapan/langkah- } \\
\text { langkah pembuatan } \\
\text { nugget sayuran }\end{array}$ & Sosialisasi & $\begin{array}{l}\text { Memberikan } \\
\text { pemahaman } \\
\text { tentang proses } \\
\text { pembuatan } \\
\text { nugget }\end{array}$ & $\begin{array}{l}\text { Menyediakan } \\
\text { tempat dan ikut } \\
\text { berpartisipasi } \\
\text { dalam kegiatan } \\
\text { serta } \\
\text { mengkonfirmasi } \\
\text { pada hal-hal } \\
\text { yang kurang } \\
\text { dipahami }\end{array}$ \\
\hline 2 & $\begin{array}{l}\text { Memberikan contoh } \\
\text { (mempraktekkan) } \\
\text { tahapan-tahapan } \\
\text { pembuatan nugget } \\
\text { sayuran }\end{array}$ & Pelatihan & $\begin{array}{l}\text { Memahami } \\
\text { proses } \\
\text { pembutan } \\
\text { nugget } \\
\text { sayuran } \\
\end{array}$ & $\begin{array}{l}\text { Memperhatikan } \\
\text { dengan seksama } \\
\text { proses } \\
\text { pembutan } \\
\text { nugget sayuran }\end{array}$ \\
\hline 3 & $\begin{array}{l}\text { Menyiapkan bahan- } \\
\text { bahan untuk pembutan } \\
\text { nugget sayuran sesuai } \\
\text { prosedur }\end{array}$ & Pendampingan & $\begin{array}{l}\text { Prosedur yang } \\
\text { diberikan } \\
\text { sebagai acuan } \\
\text { pembuatan } \\
\text { nugget }\end{array}$ & $\begin{array}{l}\text { Mempraktekkan } \\
\text { cara pembuatan } \\
\text { nugget sayuran } \\
\text { sesuai prosedur } \\
\text { yang diberikan }\end{array}$ \\
\hline
\end{tabular}




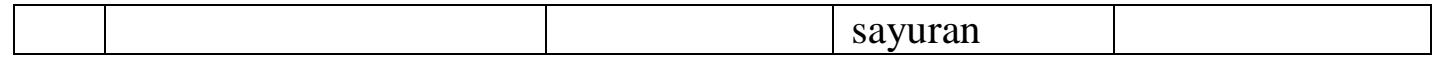

Pelatihan pembutan nugget sayuran ini dipandu oleh narasumber yang ahli dalam bidang nutrisi ternak. Materi pelatihan secara umum meliputi materi pemahaman teori pembuatan nugget sayuran, kreativitas pangan olahan, keterampilan pembuatan nugget sayuran. Adapun urutan kegiatan pelaksanaan pengabdian pembuatan nugget sayuran sebagai bahan ajar dalam pelatihan keterampilan sebagai berikut:

Tabel 2 Urutan Kegiatan

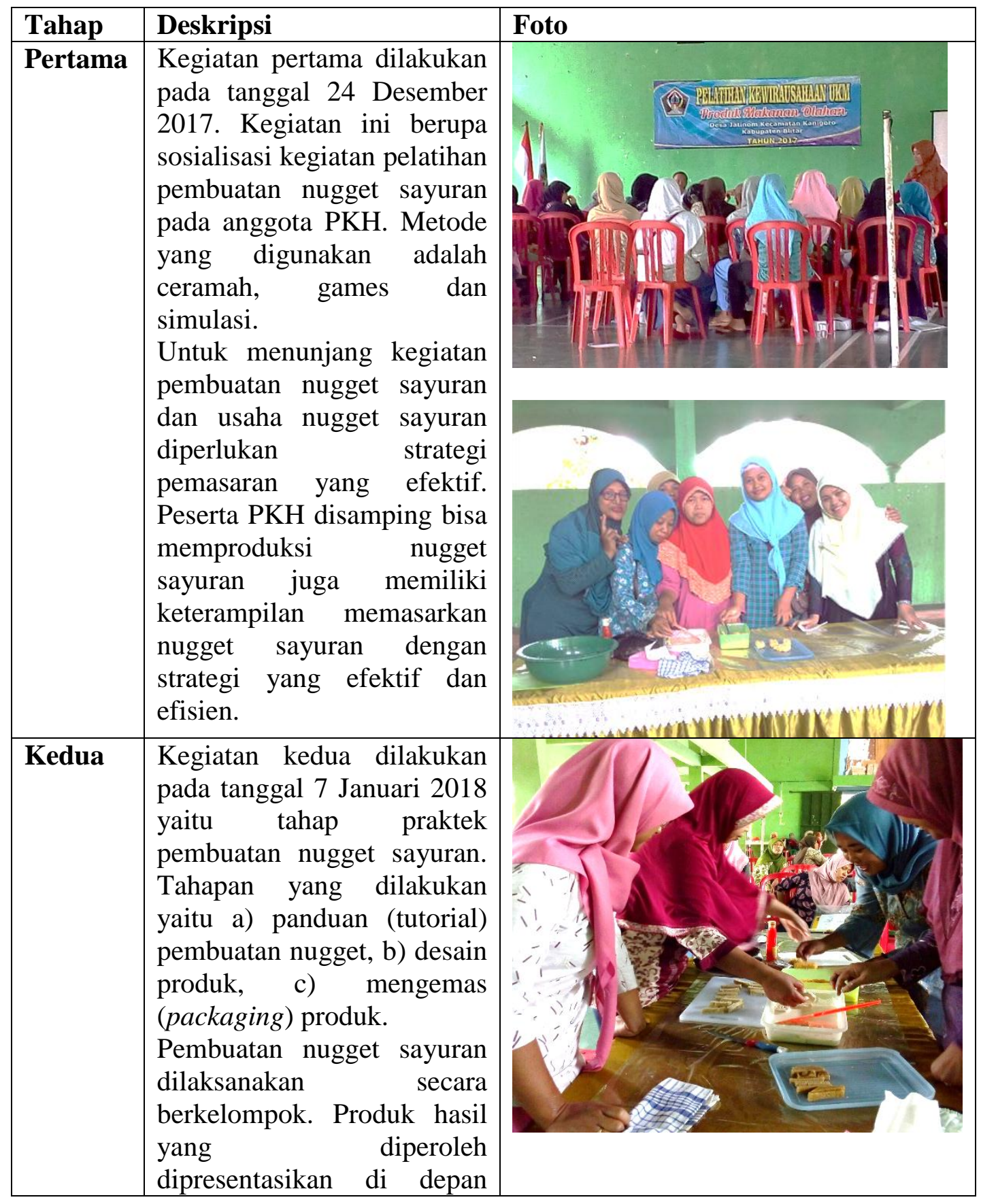

233 BRILIANT: Jurnal Riset dan Konseptual

Volume 3 Nomor 2, Mei 2018 


\begin{tabular}{|l|l|l|}
\hline & $\begin{array}{l}\text { peserta lainnya, kemudian } \\
\text { para peserta mengomentari } \\
\text { dan tanggapan dari } \\
\text { narasumber. }\end{array}$ \\
\hline
\end{tabular}

\section{PEMBAHASAN}

\section{Tahap persiapan dan pelaksanaan}

Persiapan dalam pelaksanaan kegiatan ini yaitu menyusun perencanaan yang sebenarnya sangat esensial. Perencanaan sangat erat kaitannya dengan pelaksaan program. Fungsi dari perencaan yaitu memudahkan dalam pelaksanaan program (Sanjaya, 2015). Survey yang dilakukan dalam program ini termasuk menyusun strategi program yang akan dilaksanakan. Survey sangat diperlukan untuk mengetahui kebutuhan masyarakat melalui pertanyaan-pertanyaan terstruktur dan tertuju (Control \& Prevention, 2001). Identifikasi kebutuhan masyarakat salah satu caranya adalah memberikan pelatihan dan pendampingan. Peningkatkan kualitas sumber daya manusia (SDM) merupakan suatu keharusan di era digital saat ini untuk membentuk manusia yang memiliki keterampilan dan kemandirian anggota PKH Kecamatan Jatinom Blitar. Ada beberapa cara dalam peningkatan kualitas SDM melalui pelatihan, pembinaan dan pendampingan (Zetra, 2009). Pelatihan, pembinaan dan pendampingan yang dilakukan dalam program ini untuk membentuk anggota PKH di jatinom memiliki keterampilan dalam membuat produk olahan yang inovatif yaitu nugget sayuran.

\section{Pelatihan Pembuatan Nugget Sayuran}

Pelatihan merupakan salah satu upaya untuk mendidik anggota $\mathrm{PKH}$ Jatinom Blitar yaitu berkaitan dengan pemahaman teori dan keterampilan dalam pembuatan pangan olahan (nugget sayuran). Teori pengolahan pangan yang dijadikan materi dalam pelatihan ini berorientasi pada pangan olahan yang inovatif. Pangan olahan yang inovatif memiliki daya tarik tersendiri, dimana pengolahannya secara prinsip sama. Namun, ada beberapa tambahan bahan atau mengganti bahan pangan dengan bahan yang alami yaitu sayuran. Prosen pengolahan nugget sayuran secara prinsip tidaklah berbeda dengan proses pembuatan nugget daging dan yang lainnya. Inovasi dalam pangan olahan harus mengikuti kaidah-kaidah umum yaitu mengutakan keamanan dan kesehatan konsumen serta kelayakan nutrisi yang terkandung dalam pangan olahan tersebut (Ayustaningwarno, 2014). Nugget sayuran yang dijadikan sebagai bahan pelatihan juga mementingkan aspek kesehatan, keamanan dan layak untuk dikonsumsi serta jadi usaha baru bagi anggota PKH Jatinom Blitar.

\section{Pendampingan Pembuatan Nugget Sayuran}

Pendampingan dalam pembutan nugget sayuran merupakan suatu proses untuk memudahkan masyarakat dalam mengolah nugget sayuran sehingga masalah-masalah yang timbul segera diselesaikan. Secara umum pendampingan merupakan fasilitas pelayanan oleh pendamping kepada anggota atau kliennya dalam mengidentifikasi dan memecahkan masalah serta mendorong tumbuhnya kemandirian klien secara berkelanjutan. Pendampingan juga termasuk sarana komunikasi antara pendamping dengan kaliennya. Komunikasi yang terjalin 
dengan baik maka pendamping lebih mudah dalam menggerakkan, memotivasi, mendorong dan katalisasi masalah yang lebih (Suharto, 2008).

Pendampingan di dalam program ini merupakan strategi, dimana strategi pendampingan termasuk hal yang umum dilakukan di setiap organisasi sampai lembaga pemerintahan. Strategi pendampingan sebenarnya berfungsi untuk mengoptimalkan tujuan dan mengidentifikasi sedini mungkin terjadinya masalah yang sedang dihadapi oleh anggota yang didampinginya. Oleh sebab itu, penerapan pendampingan dalam program pelatihan pembuatan nugget sayuran adalah optimalisasi kinerja klien agar lebih optimal dalam memahami materi dan proses pembuatan nugget sayuran secara mandiri dari awal sampai akhir.

\section{Tahap Evaluasi Program}

Perjalanan program pengabdian ini perlu adanya evaluasi untuk menilai suatu program agar program yang dijalankan terukur keberhasilannya. Evaluasi merupakan kegiatan yang dilakukan hubungannya dengan proses yang telah dilakukan untuk menyakatan nilai suata proses pekerjaan (Azarkeivan et al., 2011). Tahap evaluasi dalam program pengabdian ini yaitu dilaksanakan 2 kali. Kegiatan pertama dilaksanakan pada tanggal 24 Desemberi 2017 pada saat kegiatan tahap pertama yaitu pada saat sosialisasi kegiatan pelatihan, motivasi usaha dan strategi pemasaran produk nugget sayuran. Evaluasi dilaksanakan sebagai wadah bagi anggota pendamping PKH berkaitan dengan program yang dilaksanakan. Evaluasi dilakukan dalam bentuk diskusi informal untuk bertukar pikiran secara lebih leluasa mengenai manfaat, kelebihan, kekurangan dan masukan dari peserta lainnya. Adapun hasil dari evaluasi pertama menunjukkan hasil yang positif. Peserta merasakan manfaat dari materi yang disampaikan karena adanya simulasi yang memudahkan materi yang disampaikan.

Evaluasi yang kedua dilaksanakan pada tanggal 7 Januari 2018. Bentuk evaluasi yang dilakukan sama sebagaimana pada evaluasi yang pertama yaitu dalam bentuk diskusi informal mengenai hasil baik kelebihan, kekurangan serta masukan dari peserta lainnya. Hasil dari evaluasi yang kedua yaitu anggota pendamping PKH mampu membuat nugget sayuran secara berkelompok. Keberlanjutan dari program ini, denga modal materi yang didapatkan serta bahan yang sangat mudah didapat untuk membuat nugget dapat dipraktekkan secara mandiri dirumah. Hasilnya adalah tiap peserta dapat membuat nugget sayuran yang di cetak sesuai seleranya.

\section{KESIMPULAN}

Kegiatan program pengabdian bisa meningkatkan kualitas SDM kelompok pendamping anggota PKH di Jatinom untuk mengolah produk nugget sayuran sebagai makanan fast food yang aman bagi kesehatan, strategi desain produk, sehingga dapat meningkatkan produktivitas anggota kelompok pendamping PKH Jatinom, Blitar.

\section{SARAN}

Saran dalam pelaksanaan program pengabdian ini yaitu perlu adanya tindak lanjut dari pengabdian dengan perbaikan sarana yang lebih menunjang dan variasi produk yang lebih banyak guna memberikan pengetahuan yang lebih luas. 


\section{DAFTAR RUJUKAN}

Abustam, E., \& Ali, H. 2005. Dasar teknologi hasil ternak. Buku Ajar. Program A2 Jurusan Produksi Ternak Fak. Peternakan. Makasar: Universitas Hasanuddin.

Ayustaningwarno, F. 2014. Teknologi pangan; teori praktis dan aplikasi. Yogyakarta: Graha Ilmu.

Azarkeivan, A., Arjangyan, M., Hajibeigi, B., Afradi, H., Aghaeepour, M., Razjoo, F., Eshghi, P. 2011. Evaluasion and comparison of washed rbcs by closed and open systems. ZUMS Journal, 19(75): 66-76.

Buckle, K., Edwards, R., Fleet, G., \& Wootton, M. 1987. Ilmu pangan. Diterj oleh H, Purnomo dan Adiono. Jakarta: Universitas Indonesia.

Control, C.f.D., dan Prevention. 2001. Behavioral risk factor surveillance system survey questionnaire. Atlanta: US Department of Health and Human Services, Centers for Disease Control and Prevention.

Ratnani, R. 2009. Bahaya bahan tambahan makanan bagi kesehatan. Jakarta: Graha Ilmu.

Sanjaya, W. 2015. Perencanaan dan desain sistem pembelajaran.Jakarta: Kencana.

Saparinto, C., dan Hidayati, D. 2006. Bahan tambahan pangan: Jakarta: Kanisius.

Suharto, E. 2008. Pendampingan sosial dalam pemberdayaan masyarakat miskin: Konsepsi dan strategi, (Online), (http://www.policy.hu/suharto/modul. a/makindo_32. htm), diakses 8 Mei 2018.

Yuyun, A. 2007. Aneka nugget sehat nan lezat. Jakarta: AgroMedia.

Zetra, A. 2009. Strategi pengembangan kapasitas sdm pemerintah daerah dalam mewujudkan transparansi dan akuntabilitas pengelolaan keuangan daerah. Jurnal Akuntansi. 